\title{
The Impact of Asphalt Wearing Surface Thickness on Response of Two-Span Continuous Cast-in-Place Prestressed Concrete Box Girder Highway Bridge
}

\author{
Khairedin M. Abdalla ${ }^{1, *}$, Rajai Z. Al-Rousan ${ }^{1}$, Mohammed T. Obaidat ${ }^{1}$, Osama K. Nusier ${ }^{1}$, Khaldoon \\ Bani-Hani ${ }^{1}$ and Nikos D. Lagaros ${ }^{2}$
}

${ }^{1}$ Department of Civil Engineering, Jordan University of Science \& Technology, Jordan ${ }^{2}$ Department of Structural Engineering, National Technical University Athens (NTUA)

Received 19 February 2019; Accepted 10 March 2019

\begin{abstract}
This paper presents the finite element analysis (FEA) results of a two-span continuous cast-in-place prestressed concrete box girder highway bridge with various asphalt wearing surface thicknesses. The benefits of the FEA can be extremely valued when visualizing the substantial cost and time savings, the potential of signifying any attractive response at any location in the system and at any load value and, and the capability to modify any constraint of interest. Based on the analysis results, asphalt wearing surface thicknesses considerably enhances the ultimate positive and negative moments, ultimate deflection, and ultimate positive and negative stress. The stress due to truck load were below the allowable tensile and compressive strength of deck as well as the asphalt wearing surface had a strong impact on the positive stress, moderate impact on the ultimate moment and corresponding deflection, and small impact on negative stress.
\end{abstract}

Keywords: Asphalt Wearing Surface, Thickness, Two-Span Continuous, Cast-In-Place, Prestressed Concrete, Box Girder, Highway Bridge.

\section{Introduction}

The using of continuous cast-in-place concrete box girder highway bridges has increased in recent times. In construction of this type bridges having variable or constant section height, the cantilever technique can apply if the number of spans in more than two. Box girder section consists of single or more box girder based on Highway Bridge wide. Recently, many attractive research topics have arisen such as to be taken in to consideration prestressed concrete highway bridge in the analysis. Normally, bridges are analyzed by assuming that they are instantaneously built in a time. In this analysis, real material properties should be taken into account [1-6].

In this paper, the finite element analysis (FEA) using commercial software was used to simulate the response of two-span continuous cast-in-place (CIP) prestressed concrete box girder Highway Bridge with various asphalt wearing surface thicknesses $\left(\mathrm{t}_{\mathrm{ws}}=0,1,2,3,4\right.$, and 5 in.). Actual steel reinforcing details and geometry of cast-in-place prestressed concrete box girder Highway Bridge as well as various asphalt wearing surface thicknesses were considered in the FEA. The ultimate moment capacity and corresponding deflection, and stress response profile were obtained.

Table 1. FEA of Six two - span continuous CIP prestressed concrete box.

\begin{tabular}{c|c|c|c|c|c}
\hline $\begin{array}{c}\text { Thickness of } \\
\text { asphalt }\left(\mathbf{t}_{\mathbf{w s}}\right) \text {, in. }\end{array}$ & $\begin{array}{c}\text { Ultimate } \\
\text { deflection, in. }\end{array}$ & $\begin{array}{c}\text { Ultimate positive } \\
\text { moment, kips.ft }\end{array}$ & $\begin{array}{c}\text { Ultimate negative } \\
\text { moment, kips.ft }\end{array}$ & $\begin{array}{c}\text { Ultimate } \\
\text { positive stress, } \\
\text { ksi }\end{array}$ & $\begin{array}{c}\text { Ultimate } \\
\text { negative } \\
\text { stress, ksi }\end{array}$ \\
\hline 0 & 1.69 & 31300 & 47200 & 1.62 & 3.21 \\
1 & 1.82 & 33900 & 49100 & 1.80 & 3.33 \\
2 & 1.96 & 36100 & 52500 & 2.04 & 3.58 \\
3 & 2.10 & 38600 & 58200 & 2.37 & 3.82 \\
4 & 2.24 & 39800 & 60500 & 2.50 & 4.00 \\
5 & 2.38 & 40800 & 62700 & 2.58 & 4.10 \\
\hline
\end{tabular}

\section{Finite Element Analysis}

Table 1 shows the FEA of six two-span continuous CIP

*E-mail address: abdallakhairedin@yahoo.com

ISSN: 1791-2377 @ 2019 Eastern Macedonia and Thrace Institute of Technology. All rights reserved. doi:10.25103/jestr.121.20 prestressed concrete box girder Highway Bridge with various $\mathrm{t}_{\mathrm{ws}}$ of $0,1,2,3,4$, and 5 in. The ultimate compressive strength of $4.0 \mathrm{ksi}$, uniaxial tensile strength of $0.4 \mathrm{ksi}$, and initial young's modulus $\left(E_{c}\right)$ of $115 \mathrm{ksi} \mathrm{MPa}$ are needed to define the concrete failure surface. Therefore, Figure 1 shows the William and Warnke [7] which was used to defined the concrete criterion with Poisson's ratio of 0.2. 
The assumed steel reinforcement stress strain behavior is elastic-perfectly plastic material which is identical in compression and tension as shown in Fig. 1. The steel yield stress and Poisson's ratio are $60 \mathrm{ksi}$ and 0.3 . The steel plate is assumed as linear elastic material with Poisson's ratio of 0.3 and elastic modulus of $29000 \mathrm{ksi}$. Perfect bonding between the concrete and steel reinforcement was assumed. A twospan continuous cast-in-place prestressed concrete box girder highway bridge has two equal spans of length $157 \mathrm{ft}$. with a column bent as shown in Figure 2. The superstructure is 34 $\mathrm{ft}$. wide. The elevation of the bridge is shown in Figure 2.

Based on the design practice, the width of 12 in. for girders with the exterior girder flaring to $18 \mathrm{in}$. at the anchorage end and a thickness of $7 \mathrm{in}$. at the edge and $12 \mathrm{in}$. at the face of the exterior girder for the overhang were selected. The deck and soffit thicknesses depend on the clear distance between adjacent girders. $7.875 \mathrm{in}$. and $5.875 \mathrm{in}$. are chosen for the deck and soffit thicknesses respectively. The length of this flare is usually taken as one-tenth of the span length $15.7 \mathrm{ft}$. A typical section for this bridge is shown in Figure 3.
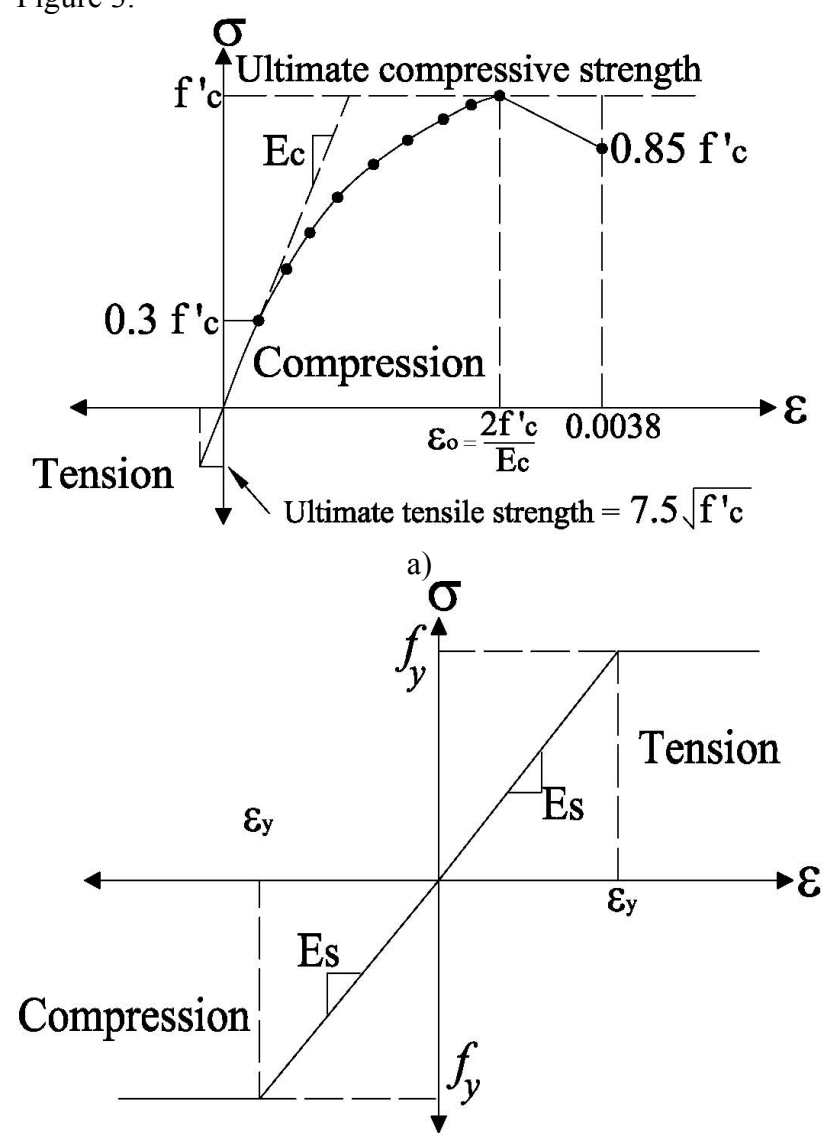

b)

Fig. 1 Concrete (a) and steel (b) stress-strain curve

Symmetrical about CL

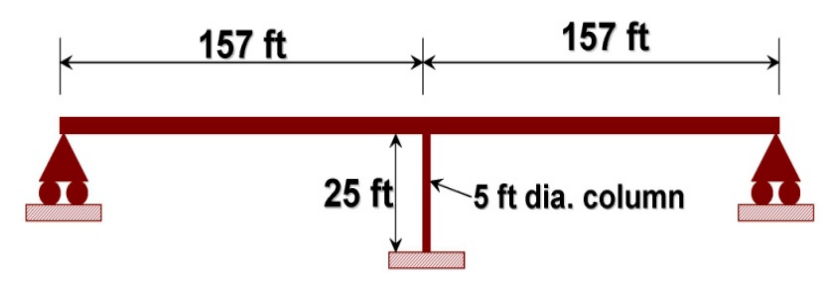

Concrete:

Initial concrete $f_{c i}^{\prime}=3,500 \mathrm{psi}, E_{c i}=3,372 \mathrm{ksi}$

Final concrete $f_{c}^{\prime}=4,000 \mathrm{psi}, E_{c}=3,600 \mathrm{ksi}$

Prestressing steel:

$f_{p u}=270 \mathrm{ksi}$ low relaxation strand

$E_{p}=28,500 \mathrm{ksi}$

Prestressing stress at jacking $f_{p j}=0.8 f_{p u}=216 \mathrm{ksi}$ Reinforcement steel:

$$
f_{y}=60 \mathrm{ksi}, E_{s}=29,000 \mathrm{ksi}
$$

Prestressing stress at jacking $f_{p j}=0.8 f_{p u}=216 \mathrm{ksi}$ Prestressing: Anchorage set thickness $=0.375 \mathrm{in}$.

Fig. 2 Continuous CIP prestressed concrete box Girder Bridge and selected materials

The thickness of soffit slab is flared to 12 in. to lower the gravity center of the superstructure at the face of a bent cap in a CIP posttensioned box girder with parabolic cable path as shown in Figure 4. The position of the jack at the end section and maximum dead load moments mainly controled the cable path. Maximum eccentricities should take place at maximum points of dead load moment and almost no eccentricity should be nearby at the jacked end section. For this study, the maximum dead load moments occur at the bent cap, close to 0.4L for Span 1 and 0.6L for Span 2.

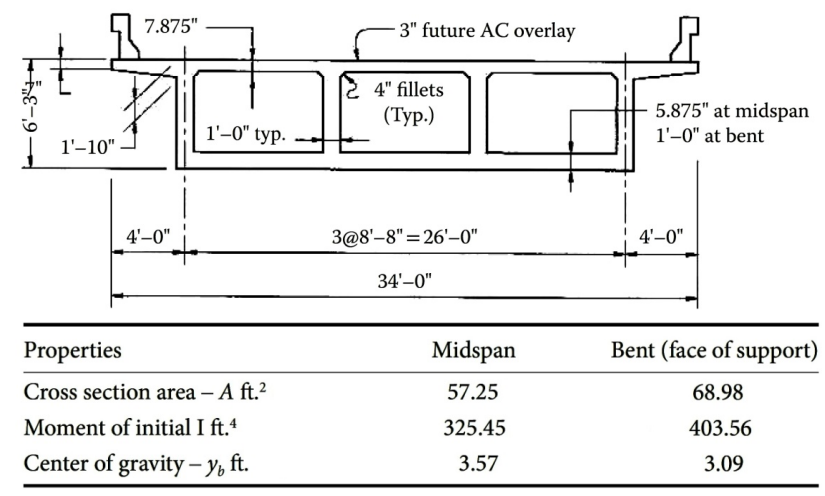

Fig. 3 Typical section of box girder

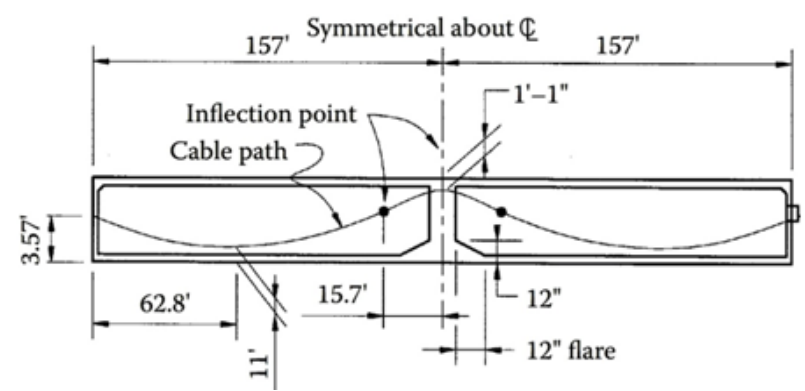

Fig. 4 Cable path

\section{Results and Discussion}

3.1. The effect of asphalt thickness on the ultimate deflection

Figure 5 shows the impact of asphalt thickness on the ultimate deflection of simulated bridge in which the ultimate of each model was normalized with respect to model without asphalt wearing surface ( $t_{\mathrm{ws}}$ of 0 in.). Inspection of Figure 5 reveals that the ultimate deflection enhancement percentage is $8 \%, 16 \%, 24 \%, 33 \%$, and $41 \%$ for asphalt thickness of 1 , $2,3,4$, and 5 , respectively, which is almost equal to 8 times 
the asphalt thickness. Therefore, the increase in the ultimate deflection is directly related to an increase in the asphalt thickness with almost with a liner relationship. This enhancement can classify as moderate impact as compared with other investigated parameters.

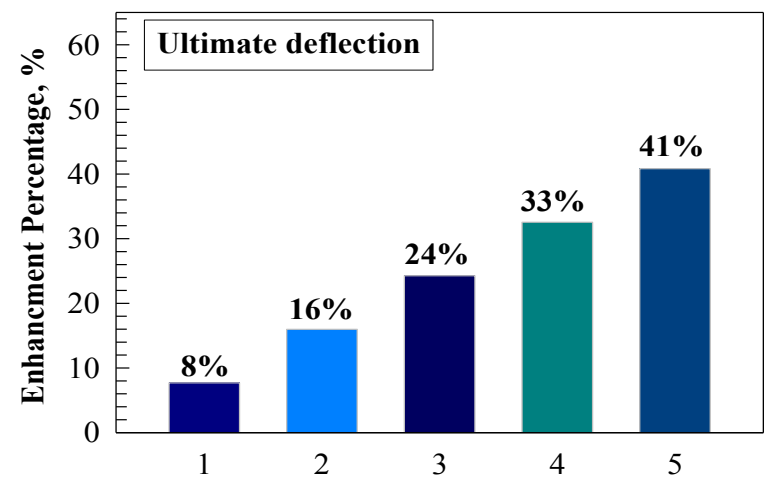

Thickness of asphalt $\left(t_{w s}\right)$, in.

Fig. 5 Ultimate deflection enhancement percentage

3.2. The effect of asphalt thickness on the ultimate moment

The impact of asphalt thickness on the ultimate moment of simulated bridge is shown in Figure 6 in which the ultimate of each model was normalized with respect to model without asphalt wearing surface ( $t_{w s}$ of 0 in.). Inspection of Figure 6 reveals that the ultimate positive moment enhancement percentage for asphalt thickness of 1,2 , and 3 in. is the same as the enhancement of deflection. But the ultimate positive moment enhancement percentage for asphalt thickness of 4 and $5 \mathrm{in}$. is the less than the enhancement of deflection.
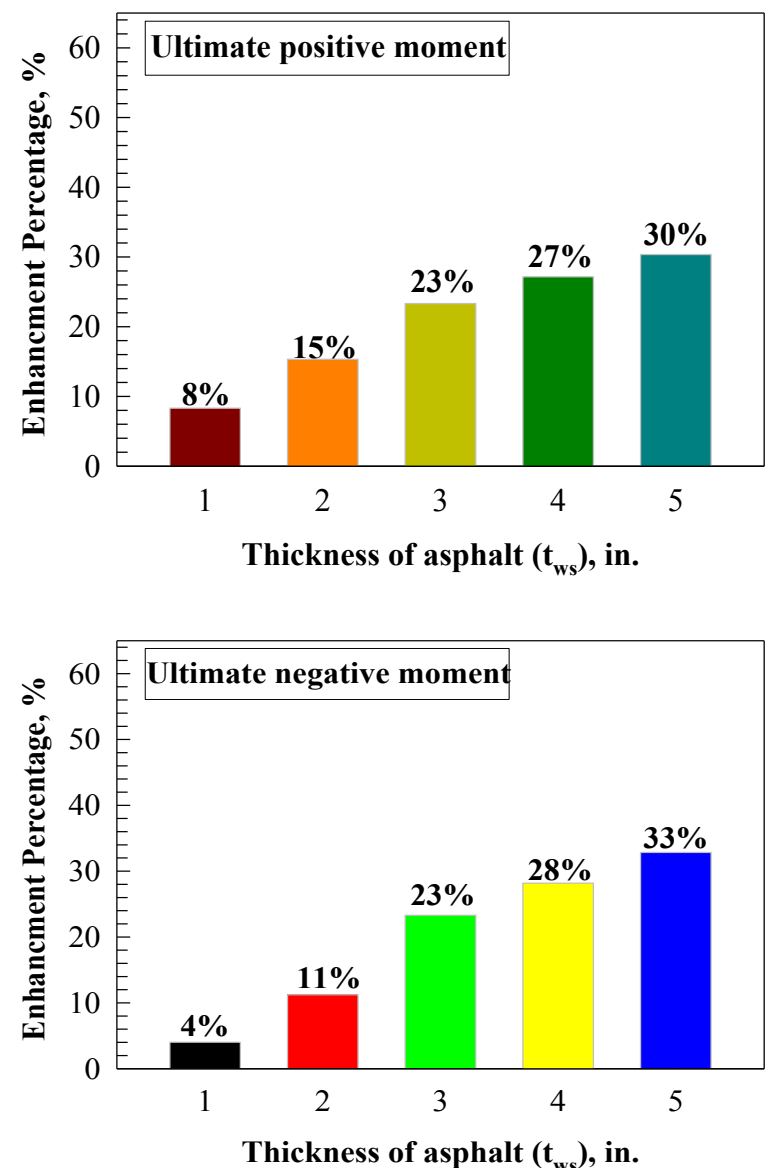

Fig. 6. Ultimate moment enhancement percentage
On the other hand, the ultimate negative moment enhancement percentage for asphalt thickness of 1 and 2 in. is almost half the positive moment enhancement percentage. But the ultimate negative moment enhancement percentage for asphalt thickness of 3,4 and 5 in. is the same as the enhancement of positive moment enhancement percentage. These enhancements can categorize as modest impact as compared with enhancement of deflection.

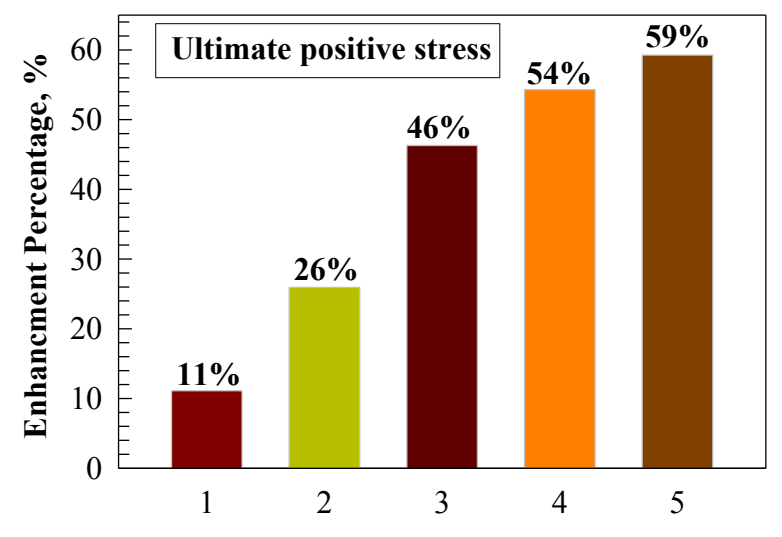

Thickness of asphalt $\left(t_{w s}\right)$, in.

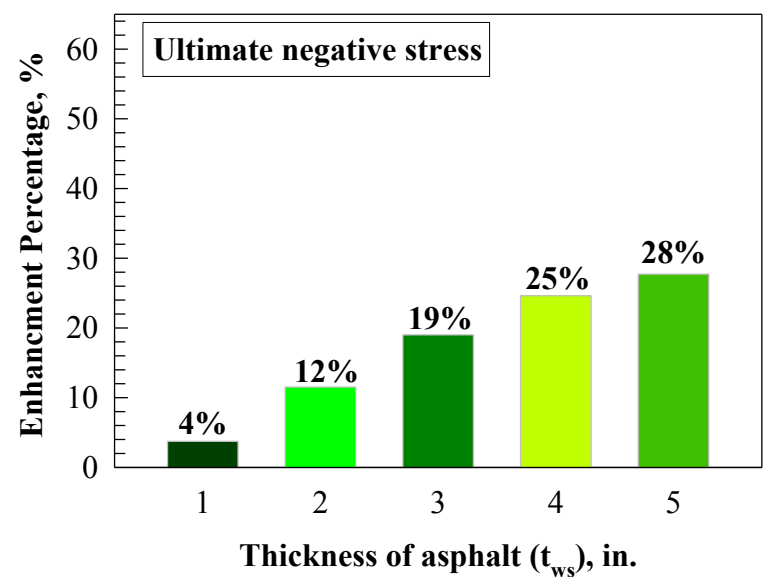

Fig. 7. Ultimate stress enhancement percentage

\subsection{The effect of asphalt thickness on the stress}

Figure 7 shows the impact of asphalt thickness on the ultimate positive and negative stress of simulated bridge in which the ultimate of each model was normalized with respect to model without asphalt wearing surface $\left(t_{w s}\right.$ of 0 in.). Inspection of Figure 7 reveals that the ultimate positive stress enhancement percentage is $11 \%, 26 \%, 46 \%, 54 \%$, and $59 \%$ for asphalt thickness of $1,2,3,4$, and 5, respectively, which is almost equal to 2 times deflection enhancement percentage. Therefore, the increase in the ultimate deflection is not directly related to an increase in the asphalt thickness with almost with a nonlinear relationship. This enhancement can classify as strongest impact as compared with other investigated parameters. On the other hand, the ultimate negative stress enhancement percentage is $4 \%, 12 \%, 19 \%$, $25 \%$, and $28 \%$ for asphalt thickness of $1,2,3,4$, and 5 , respectively. This enhancement can classify as a tiny impact as compared with other investigated parameters. Typical deflection and stress profile were shown in Figures 8 and 9. 

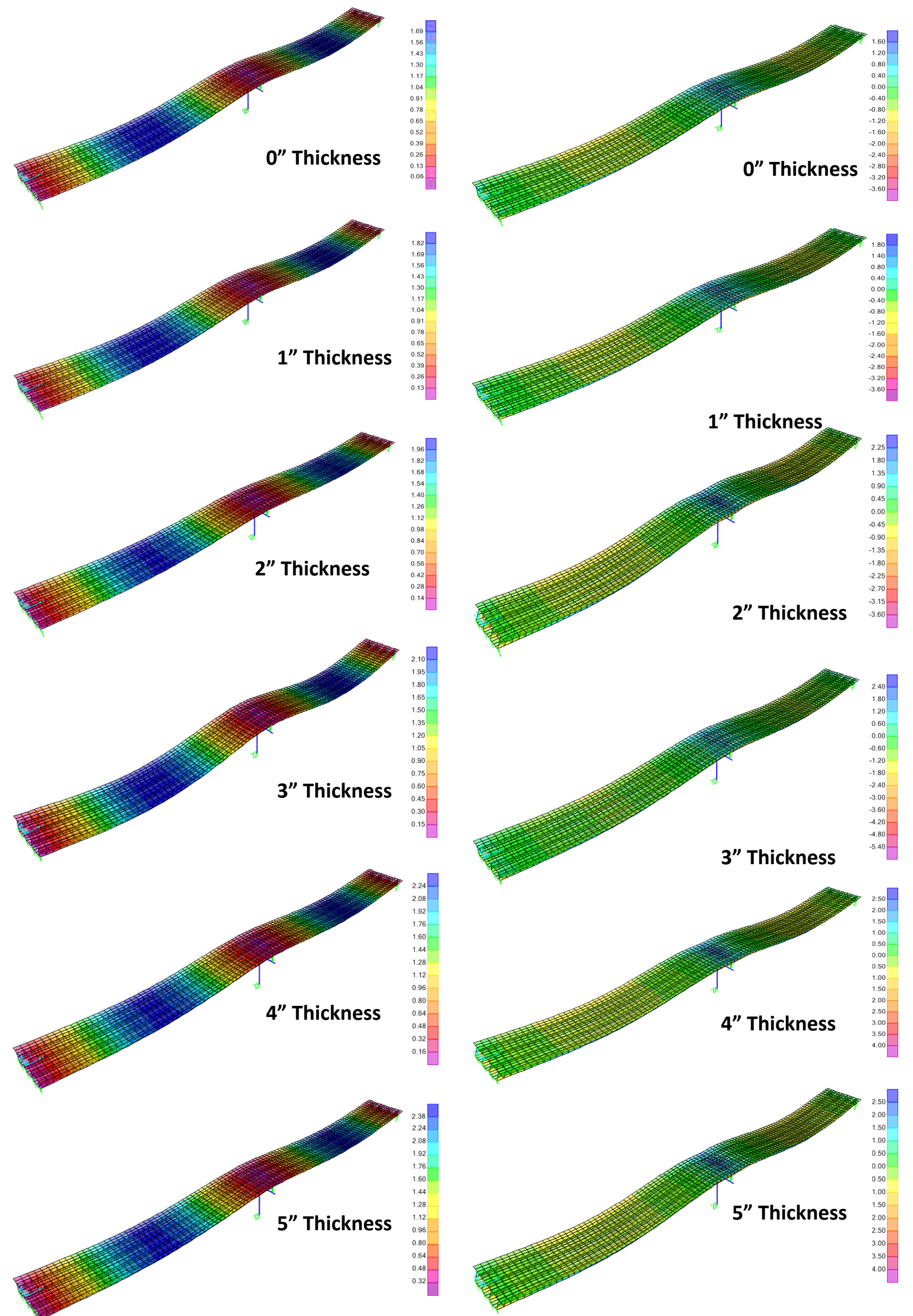

Fig. 8 Deflection profile versus asphalt thickness

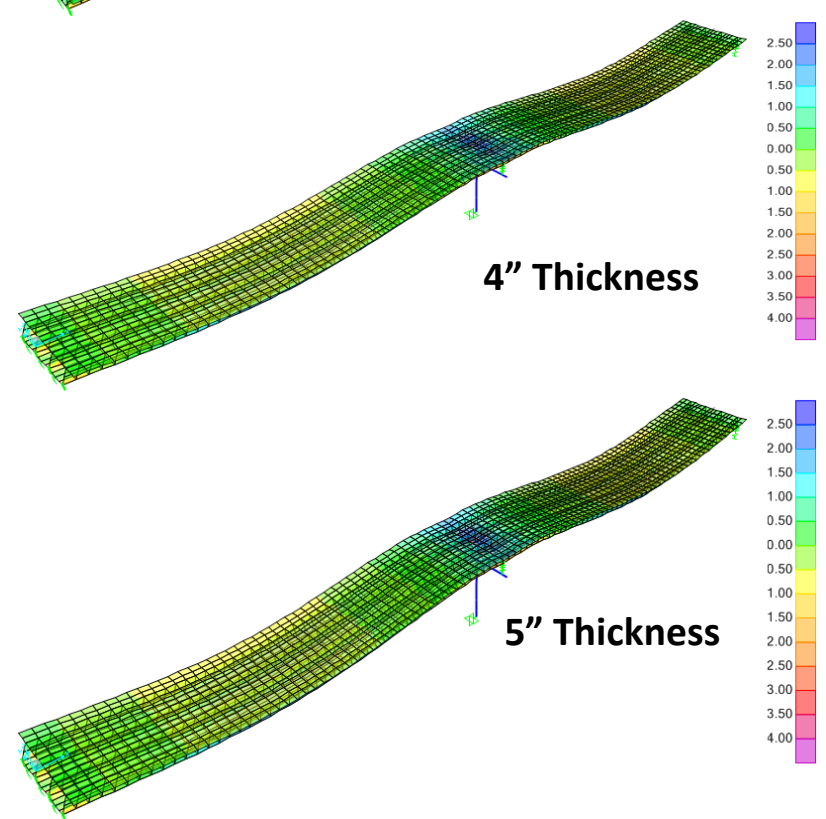

Fig. 9 Stress profile versus asphalt thickness 


\section{Conclusions}

Asphalt wearing surface thicknesses is very efficient in improving the ultimate positive and negative moments, ultimate deflection, and ultimate positive and negative stress of a two-span continuous cast-in-place prestressed concrete box girder highway bridge. Increasing asphalt wearing surface thicknesses leads to a strong impact on the positive stress, moderate impact on the ultimate moment and corresponding deflection, and small impact on negative stress. Also, asphalt wearing surface thickness of $4 \mathrm{in}$. is the optimum thickness and this is based on the ultimate moment capacity and corresponding deflection. Stress and deflection response profile were plotted for twospan continuous cast-in-place prestressed concrete box girder Highway Bridge. This finite element model can be used in additional studies to develop design rules for effect of concrete strength and cable profile as well as prestressing level on the bridge behavior.

\section{Acknowledgement}

Part of this work has been supported by the OptArch Project - Optimization Driven Architectural Design of Structures (H2020-Rise-2015). Their support is highly acknowledged. The authors would like also to thank JUST for its support.

This is an Open Access article distributed under the terms of the Creative Commons Attribution License

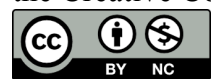

\section{References}

[1] Al-Rousan, R.Z., Issa, M.A. "The effect of beam depth on the shear behavior of reinforced concrete beams externally strengthened with carbon fiber-reinforced polymer composites." Advances in Structural Engineering, 19(11), p. 769-1779, (2016).

[2] Al-Rousan, R., Haddad, R.H., Al Hijaj, M.A. "Optimization of the economic practicability of fiber-reinforced polymer (FRP) cablestayed bridge decks," Bridge Structures; 10(4), p. 129-143, (2014).

[3] Issa, M.A., Idriss, A.T., Kaspar, I.I., and Khayyat, S.Y. "Full Depth Precast and Precast, Prestressed Concrete Bridge Deck Panels." PCI Journal; 40(1), p. 59-80, (1995).

[4] Issa, M.A., Yousif, A.A., and Issa, M.A. "Experimental Behavior of Full-Depth Precast Concrete Panels for Bridge Rehabilitation." ACI Structural Journal; 97(3), p. 397-407, (2000).
[5] Issa, M.A., Yousif, A.A., Issa, M.A., Kaspar, I.I., and Khayyat, S.Y. "Analysis of Full Depth Precast Concrete Bridge Deck Panels.” PCI Journal; 43(1), p. 74-85, (1998).

[6] Issa, M.M., Salas, J.S., Shabila, H.I., and Alrousan, R.Z. "Composite Behavior of Prefabricated Full-Depth Precast Concrete Panels Installed on Precast Prestressed Girders." PCI Journal; 51(5), p. 132-145, (2006).

[7] William, K. J. and Warnke, E. P. "Constitutive Model for the Triaxial Behavior of Concrete," Proceedings, International Association for Bridge and Structural Engineering, 19, ISMES, Bergamo, Italy, p. 11, (1975). 